\section{Category}

Synthesis of

Heterocycles

Key words

trifluoropyrimidinylborates

cross-coupling

chemoselectivity

thiobenzofurans

D. L. COUSINS, P. FRICERO, K. P. M. KOPF, E. J. MCCOLL, W. CZECHTIZKY, Y. H. LIM, J. P. HARRITY* (UNIVERSITY OF SHEFFIELD, UK)

Pyrimidin-6-yl Trifluoroborate Salts as Versatile Templates for Heterocycle Synthesis

Angew. Chem. Int. Ed. 2021, 60, 9412-9415, DOI: 10.1002/anie.202101297.

\title{
Synthesis of Heterocycles from Potassium Trifluoro(pyrimidin-4-yl)borate Salts
}

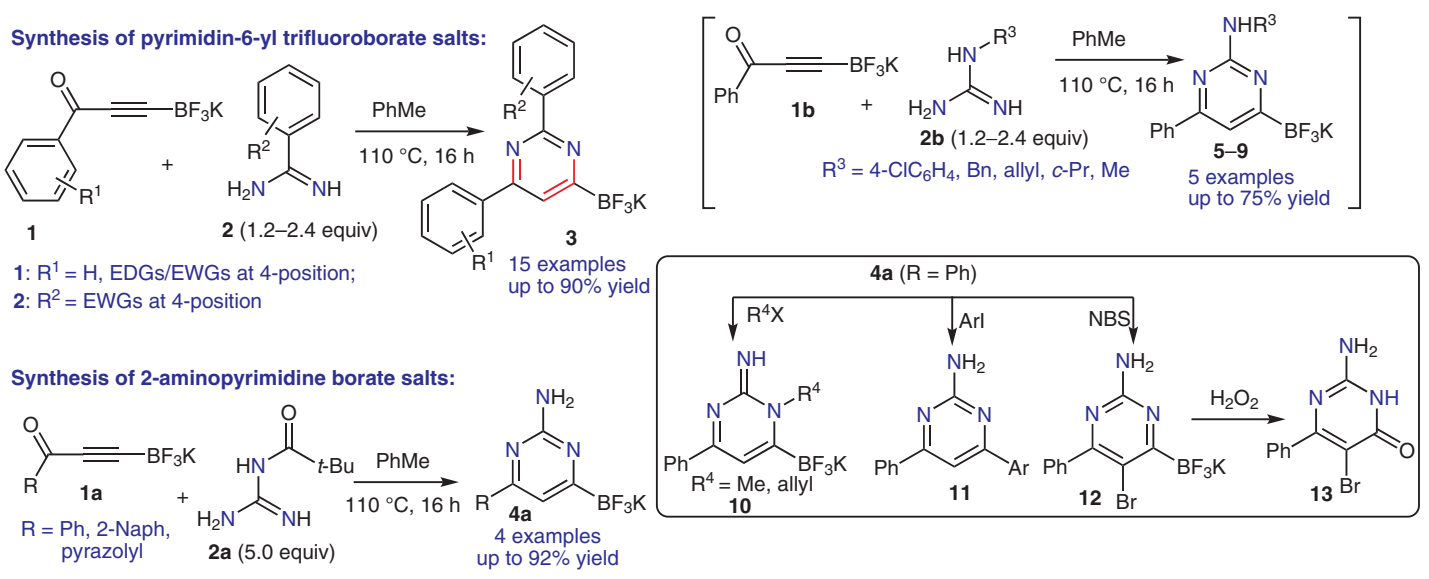

Significance: Reported is a new method for synthesizing trifluoro(pyrimidin-4-yl)borate salts 3 in high yields by the condensation of ynone trifluoroborates 1 with amidines 2 . Products $\mathbf{3}$ contain a trifluoroborate group at the $\mathrm{C} 4$ position, and this chemistry is highlighted by the unique ability of the trifluoroborate group to undergo chemo- and regioselective reactions at other positions on the pyrimidine scaffolds. Compounds 1 ( $\mathrm{R}^{1}=\mathrm{EDG}$, EWG) were well tolerated, affording the corresponding products 3. Pyrazole- and alkyl-substituted ynone trifluoroborates also underwent smooth condensations with amidines $\mathbf{2}$ to afford products 3 . The reaction of the ynone salts $1 \mathbf{a}$ with amidines $2 \mathrm{a}$ gave the 2 aminopyrimidines $4 \mathrm{a}$, whereas the $\mathrm{N}$-substituted guanidines $\mathbf{2 b}$ gave a range of $\mathrm{N}$-substituted analogues 5-9. These compounds were isolated as single regioisomers, and the regioselectivity was assigned by $\mathrm{X}$-ray crystallographic analysis in the case of $6\left(R^{3}=B n\right)$.
Comment: Pyrimidines are present in nucleic acids and many biologically active compounds, including numerous pharmaceutical and agrochemical products whose syntheses are known (R. Abderrahim, E. Leclerc, J.-M. Campagne Eur. J. Org. Chem. 2017, 2856). The synthesized C4 borylated pyrimidines are stable toward strongly nucleophilic amidines and guanidines, as well as alkylating agents, and even bromine. A reaction route for elaboration of a suitably activated $\mathrm{C}-\mathrm{B}$ bond was also demonstrated. The potential of the products to undergo further reaction was demonstrated by transformations of $\mathbf{4 a}$ into products $\mathbf{1 0 - 1 3}$ under various reaction conditions. 